\title{
The effects of care bundles on patient outcomes: a systematic review and meta- analysis
}

\author{
Jacqueline F. Lavallée $e^{1,2,3^{*}}$, Trish A. Gray ${ }^{1,2}$, Jo Dumville ${ }^{1,2}$, Wanda Russell ${ }^{4}$ and Nicky Cullum ${ }^{1,2,5}$
}

\begin{abstract}
Background: Care bundles are a set of three to five evidence-informed practices performed collectively and reliably to improve the quality of care. Care bundles are used widely across healthcare settings with the aim of preventing and managing different health conditions. This is the first systematic review designed to determine the effects of care bundles on patient outcomes and the behaviour of healthcare workers in relation to fidelity with care bundles.

Methods: This systematic review is reported in line with the PRISMA statement for reporting systematic reviews and meta-analyses. A total of 5796 abstracts were retrieved through a systematic search for articles published between January 1, 2001, to February 4, 2017, in the Cochrane Central Register for Controlled Trials, MEDLINE, EMBASE, British Nursing Index, CINAHL, PsychInfo, British Library, Conference Proceeding Citation Index, OpenGrey trials (including cluster-randomised trials) and non-randomised studies (comprising controlled before-after studies, interrupted time series, cohort studies) of care bundles for any health condition and any healthcare settings were considered. Following the removal of duplicated studies, two reviewers independently screen 3134 records. Three authors performed data extraction independently. We compared the care bundles with usual care to evaluate the effects of care bundles on the risk of negative patient outcomes. Random-effect models were used to further explore the effects of subgroups.
\end{abstract}

Results: In total, 37 studies (6 randomised trials, 31 controlled before-after studies) were eligible for inclusion. The effect of care bundles on patient outcomes is uncertain. For randomised trial data, the pooled relative risk of negative effects between care bundle and control groups was 0.97 [95\% Cl 0.71 to 1.34; 2049 participants]. The relative risk of negative patient outcomes from controlled before-after studies favoured the care bundle treated groups $(0.66$ [95\% Cl 0.59 to $0.75 ; 119,178$ participants]). However, using GRADE, we assessed the certainty of all of the evidence to be very low (downgraded for risk of bias, inconsistency, indirectness).

Conclusions: Very low quality evidence from controlled before-after studies suggests that care bundles may reduce the risk of negative outcomes when compared with usual care. By contrast, the better quality evidence from six randomised trials is more uncertain.

Trial registration: PROSPERO, CRD42016033175

Keywords: Care bundle, Effectiveness, Implementation fidelity, Behaviour change

\footnotetext{
* Correspondence: jacqueline.lavallee@manchester.ac.uk

'Division of Nursing, Midwifery and Social Work, University of Manchester,

Manchester Academic Health Science Centre, Room 3.331, Jean McFarlane

Building, Oxford Road, Manchester M13 9PL, England

${ }^{2}$ Collaboration for Leadership in Applied Health Research and Care (CLAHRC)

Greater Manchester, Manchester, England

Full list of author information is available at the end of the article
} 


\section{Introduction}

One of the main purposes of health research is to optimise health and healthcare by identifying effective healthcare interventions. Nevertheless, health research will only improve patient outcomes if the findings of research can be implemented into practice (where this is warranted) [1-3]. The translation of research findings into practice is a slow process [4]. Thus, a goal of implementation research is to improve patient outcomes by identifying the effective ways of translating research findings into practice [1]. Improving the quality of care and increasing research-informed practice has received much interest over the past decade [5-8]. Research-informed practice requires healthcare professionals to work and think differently [9] because providing the evidence is necessary but alone is not sufficient $[10,11]$. So, more recently, research has looked at how we might change the behaviour of healthcare workers to facilitate the uptake of research-informed practice in healthcare [12-14].

To improve the quality of care and reduce the variations in care within intensive care units (ICUs), the Institute for Healthcare Improvement introduced the notion of care bundles [15, 16]. Care bundles contain three to five evidence-informed practices, which need to be delivered collectively and consistently with the aim of improving patient outcomes [16]. The Institute for Healthcare Improvement recommends that fidelity with care bundles should be at least $95 \%$ and every eligible patient should receive all of the elements included within the care bundle unless medically contraindicated [16]. Care bundles are used within healthcare for many different conditions (e.g. to prevent: ventilator-associated pneumonia, pressure ulcers). Whilst the elements of care within the care bundles formalise care, their success will be influenced by the implementation processes used to support the care bundle use in practice (e.g. shaping of knowledge, monitoring and feedback) [17]. Consequently, the behaviours of healthcare workers need to be targeted as part of the intervention [18].

Interventions aimed at changing health behaviours are often complex and comprise several components which have a synergistic effect [19]. Thus, care bundles are sometimes regarded as 'complex interventions' due to the number of components and their interaction within the care bundle; the context within which the care bundle is implemented; the number and variability of outcomes; the extent to which the care bundle can be tailored and the difficulty of performing the care bundle tasks. The Medical Research Council's framework for developing and evaluating complex interventions recommends grounding complex interventions in theory to increase the likelihood of effectiveness [19]. Capitalising on behaviour change theory is important as the factors which influence the target behaviour; the active components of the intervention and the delivery of the intervention can be identified and selected [13].
Behaviour change techniques are the observable and replicable components of behaviour change interventions, often referred to as the 'active ingredients' [2022]. Previous studies reporting the use of behaviour change interventions have employed a number of different behaviour change techniques, but they have been defined differently or unclearly which limits the evaluation and replication of these interventions [23]. To address this issue, a taxonomy of 93 behaviour change techniques [22] was developed and can be used to identify intervention components, enabling the standardisation of terms as well as the comparison of behaviour change techniques across studies. Feedback on outcomes of behaviour, prompts/cues and instruction on how to perform a behaviour are examples of behaviour change techniques commonly used to facilitate a behaviour change in healthcare workers [17, 24]. Identifying the specific behaviour change techniques employed during the implementation of care bundles could enable researchers and healthcare workers to understand which components were key when the implementation of a care bundle was successful. Moreover, by using standardised behaviour change language, comparisons with other care bundles in implementation research will be possible. Such standardised language and comparisons will increase our knowledge of the most suitable methods for implementing care bundles and facilitate the prediction and explanation of any subsequent behaviour change [25].

To date, systematic reviews of care bundles have been condition [26-35] or setting-specific [36-38]. Very few systematic reviews have explored the common behaviour change techniques employed to facilitate the implementation of care bundles and it is unknown which factors may impact on the success of care bundles. Therefore, the objectives of this review were to evaluate the effects of care bundles as tools for reducing the number of negative patient outcomes, to identify potentially effective approaches to the implementation of care bundles and to explore whether there are plausible factors that modify the effects of care bundles (e.g. healthcare settings, fidelity with the bundle, the number of care bundle elements, different implementation techniques).

\section{Methods}

To maximise clarity and transparency, we have reported our review in line with the PRISMA statement for the reporting of systematic reviews and the meta-analyses of studies evaluating healthcare interventions [39].

\section{Eligibility criteria}

We applied the following eligibility criteria: 


\section{Study design}

Randomised trials (including cluster-randomised trials) and non-randomised trials (comprising controlled beforeafter studies, interrupted time series studies and cohort studies) were eligible for inclusion. Additionally, interrupted time series studies were required to have at least three data points both before and after the intervention. Conference abstracts were eligible if we were able to contact the authors and they provided sufficient information to allow a decision to be made regarding inclusion based on our eligibility criteria. We were only able to include English language articles due to resource constraints.

\section{Participants}

Evaluations of the impact of care bundles on patients of any age, in any setting and with any condition were eligible for inclusion.

\section{Intervention}

Studies were eligible for inclusion if they evaluated a care bundle. Our operational definition of a care bundle was informed by the Institute for Healthcare Improvement:

'a small, straightforward set of evidence-based practices-generally three to five-that, when performed collectively and reliably, have been proven to improve patient outcomes' [16].

\section{Outcome measures}

Primary outcome measures for the review were the number of negative patient outcomes (e.g. the number of central line-associated bloodstream infections per 1000 catheter days; mortality) and implementation fidelity (i.e. adherence with the care bundle).

Where study eligibility was in doubt due to a lack of information in the publication (e.g. conference abstracts), we attempted to contact the authors.

\section{Search strategy}

The search strategy was developed using the terms based on intervention and outcomes (see Additional file 1 for search terms). To maximise retrieval, we searched the following databases: British Nursing Index $(n=811)$, CINAHL $(n=290)$, MEDLINE $(n=985)$, EMBASE $(n=986)$, CENTRAL $(n=1623)$, PsycINFO $(n=1101)$, British Library $(n=0)$, Conference Proceedings Citation Index $(n=0)$ and OpenGrey $(n=0)$. As the Institute for Healthcare Improvement developed the notion of care bundles in 2001, searches were restricted to the studies conducted during or after 2001 until 4 February 2017. The reference lists of the included articles were also checked.

\section{Data collection and analysis Selection of studies}

References were managed in EndNote (Clarivate Analytics, Philadelphia), which assisted with the identification and removal of duplicate studies, and imported into Covidence Systematic Review Software (Melbourne). Two reviewers (JL, WR), who were not blinded to study authors, screened the titles and abstracts before conducting a fulltext review of the remaining studies. Where discrepancies occurred, we reached agreement through discussion.

\section{Data extraction}

Three reviewers (JL, WR, TG) independently performed data extraction using a pre-defined extraction sheet. We extracted the following data:

- Title

- Aims/objectives

- Study design

- Country of study

- Patient population (inclusion and exclusion criteria, age, co-morbidities, sex)

- Healthcare settings

- Care bundle content: the number and nature of the care bundle elements; the characteristics of those delivering and receiving the care bundle; the frequency with which the components were delivered and for how long

- Intervention content: we considered a care bundle to have been informed by theory if the authors explicitly stated using a relevant theory when describing either the development or implementation of the care bundle.

- Behaviour change techniques: a post hoc approach was taken where we retrospectively assigned the reported implementation techniques (e.g. training session) to one of the 93 behaviour change techniques according to the Behaviour Change Technique Taxonomy Version 1 [22]. Where several behaviour change techniques within the same category were used, this was counted as one (e.g. if 'monitoring of behaviour' and 'feedback on behaviour' were used, according to the taxonomy, these would be classed as 'feedback and monitoring').

- Fidelity data relating to adherence to the care bundles were extracted from the data provided in the papers.

- Duration of follow-up

- Outcome measures

- Outcome data

- Funding source

\section{Risk of bias assessment}

Three reviewers (JL, WR, TG) independently assessed the included studies for their risk of bias, and we 
resolved disagreements through discussion. Interrater reliability was calculated using Cohen's kappa [40]. The Cochrane Collaboration tool for assessing risk of bias [41] was used for randomised trials. The Cochrane Risk of Bias Assessment Tool: for Non-Randomised Studies of Interventions [42] was used to assess the risk of bias for nonrandomised studies. We assessed the inter-rater reliability for the risk of bias judgements of the randomised trials $(K=0.82)$ and non-randomised studies $(K=0.70)$.

\section{Measures of treatment effect}

For dichotomous outcomes (e.g. negative patient outcomes), we calculated the risk ratio (RR) with 95\% confidence intervals (CIs). A RR value of $<1$ favoured the use of the care bundle (i.e. indicated a lower risk of the negative events with care bundles) and a value $>1$ indicated more favourable outcomes when usual care was applied (i.e. there was a higher risk of the negative events with care bundles). Fidelity with the care bundle was recorded as a percentage indicating the extent to which the patient received either a particular care bundle element or the whole care bundle. For continuous data using the same scale, we used the difference in means (MD) with 95\% CIs, and when different scales were used, we calculated the standardised difference in means (SMD) with 95\% CIs.

\section{Assessment of heterogeneity}

We considered clinical and methodological heterogeneity: that is how participants, outcomes and characteristics (e.g. number of care bundle elements) varied between studies. This assessment was complemented by an assessment of statistical heterogeneity using the chisquared test (statistically significant heterogeneity was indicated by a significance level of $P<0.1$ ). In addition, $I^{2}$ [43] was also calculated, which is the percentage of total variation across studies due to heterogeneity. We followed the rubric that an $I^{2}$ of $0-40 \%$ indicates low heterogeneity [43] whilst 75 to $100 \%$ indicates very high heterogeneity [44]. A fixed effect analysis was planned when minimal clinical heterogeneity was supported by $0 \%$ statistical heterogeneity [45]. In cases where statistical heterogeneity was greater than $0 \%$, we planned to use a random effects model.

\section{Assessment of reporting biases}

We planned to present funnel plots for meta-analyses comprising of 10 randomised trials or more to detect possible publication bias [41].

\section{Dealing with missing data}

We conducted a complete case analysis and dealt with missing data issues in the risk of bias assessment.

\section{Data synthesis}

A narrative summary of the characteristics of the included studies and a forest plot of study findings are presented. We planned to pool data across studies where possible but we anticipated high levels of clinical and methodological heterogeneity due to the broad review question. Thus, we planned to explore the heterogeneity by conducting considered subgroup analyses using Comprehensive Meta-Analysis software [46]. We prespecified that the following study features may potentially explain some of the heterogeneity: study design, health condition, healthcare setting, the number of care bundle elements, the number of behaviour change techniques and the levels of fidelity with the care bundles. The first author (JL) undertook the data analysis and synthesis, and it was validated by the third author (JD). We pooled the data from each of the subgroups using a random-effect model and reported the principle measures of effect using 95\% confidence intervals with risk ratios. As we present data from a random effect model, the reported results are the average effect for each subgroup. We used this approach to explore whether there was an underlying effect of care bundles and to guide future research $[47,48]$.

\section{Sensitivity analysis}

We planned to perform sensitivity analyses to explore the effect of the risk of bias by conducting a metaanalysis both with and without the studies assessed as being at a high or unclear risk of bias. However, this was not possible due to the limited number of studies assessed as being at a low risk of bias.

\section{Results}

The initial search generated 5796 records, and a total of 37 met the criteria for inclusion in the review (Fig. 1). The reasons for excluding records are stated in Fig. 1.

\section{Study characteristics}

The characteristics of each study are presented in detail in Additional file 2. We identified four individually randomised trials [49-52], two cluster randomised trials $[53,54]$ and 31 controlled before-after studies [55-82]. All of the included studies reported on care bundles within inpatient settings. A variety of health conditions were targeted with ventilator-associated pneumonia being the most common $[56,59,61,66,71,74,82]$. Two studies reported the implementation of two bundles [53, 73] and one study reported on three care bundles [63]. Descriptions of the people delivering the care bundles were limited. The duration of the intervention varied from 3 months to 7.5 years (the median length of time was 31.5 months). 


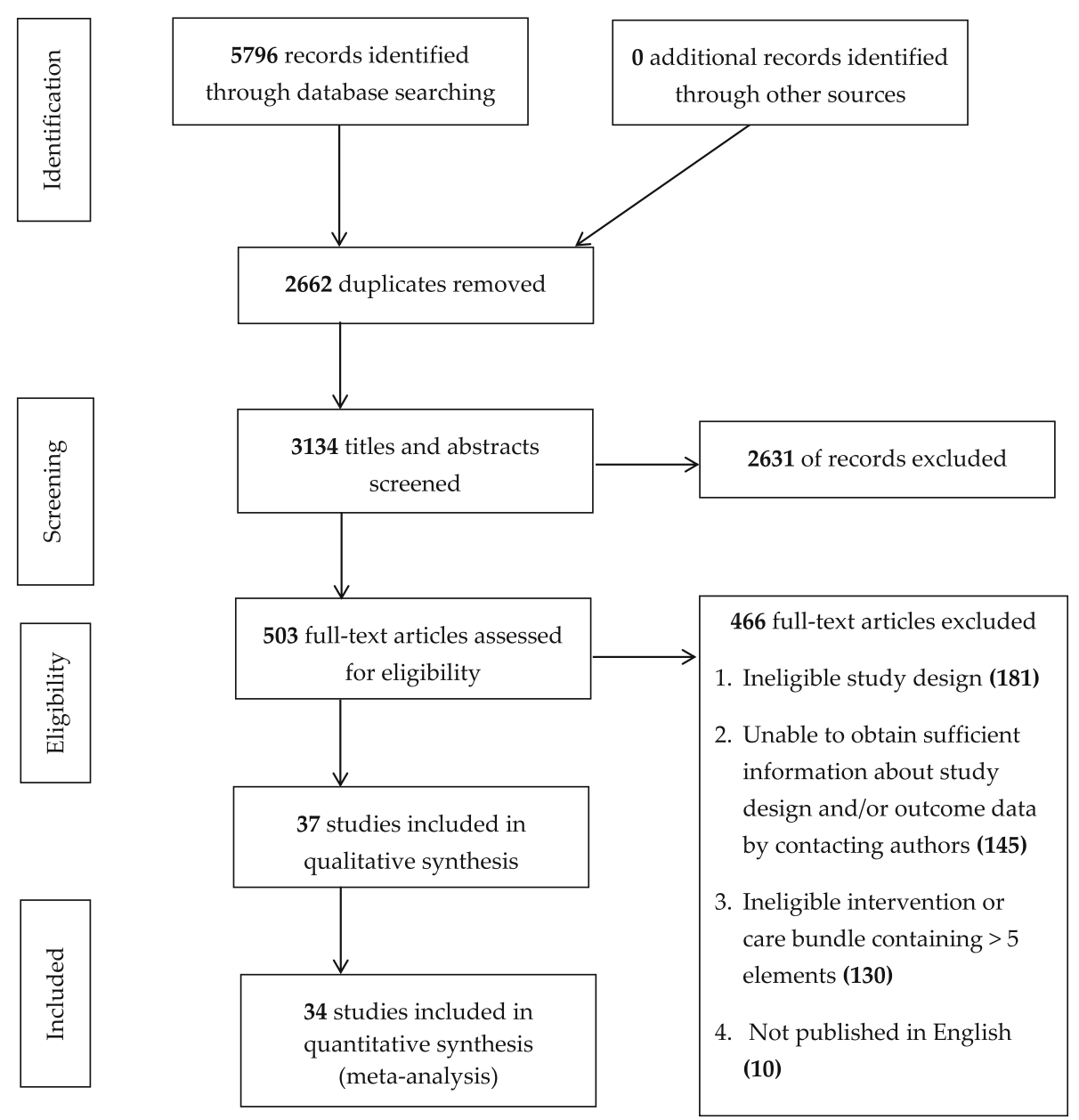

Fig. 1 PRISMA flow diagram to identify eligible studies

A variety of behaviour change techniques were used to facilitate the implementation and the potential success of the care bundles (see Additional file 2). However, no study reported a theoretical basis for choosing the various behaviour change techniques. 'Feedback and monitoring' was the most commonly reported behaviour change technique used to support the implementation of the care bundles (reported in 22 studies) (see Additional file 2). Eight studies reported using an implementation framework or psychological theory to inform the implementation of the care bundles $[42,48,55,63-66,72]$.

\section{Risk of bias}

Summaries of the risk of bias assessments for the included randomised trials and non-randomised trials are presented in Additional file 3. The cluster-randomised trial [53], which aimed to improve the consistency of stroke care through the implementation of a care bundle, was assessed as being at low risk of bias. Three randomised trials and one cluster-randomised trial were at high risk of bias [50-52, 54], and one study was unclear for risk of bias due to poor reporting [49]. Two of the controlled before-after studies were assessed as having a low risk of bias [75, 83], eight were assessed to be at a moderate risk of bias $[55,58,66,69,72,76,84], 15$ were assessed to be at a serious risk of bias $[56,57,59-65,67$, $68,71,74,78,85]$ and seven were assessed to be at a critical risk of bias $[70,73,77,80,81]$.

\section{Effects of care bundles}

There was a substantial variation in the effect of care bundles across the individual studies, ranging from a RR of 0.08 (care bundle decreased the risk of ventilator-associated pneumonia [74]) to a RR of 1.88 (care bundle increased the risk of surgical site infections [50]) (see Fig. 2) (Chi-squared $=P<.1 ; I^{2}=86 \%$ ). As a consequence of this heterogeneity, we did not pool all of the data into one analysis. Rather, we used subgroup analysis to explore cautiously whether specific methodological features and intervention aspects of the care bundles might impact on the relative effects (see Fig. 3). One randomised trial [53] and one controlled before-after study [72] did not report any patient outcomes, 


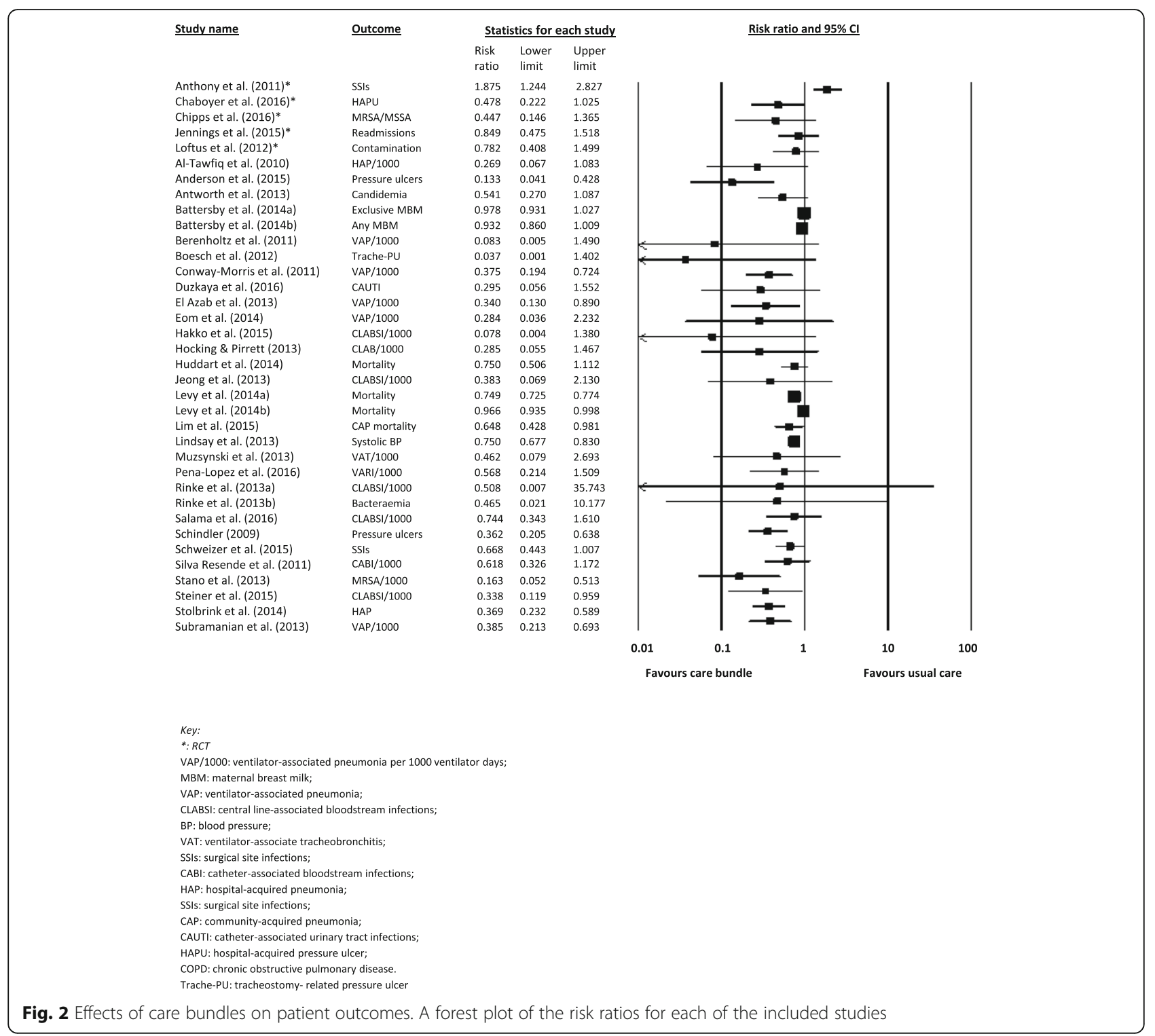

only fidelity with the care bundles, and it was not possible to re-analyse the findings from Smith [77] due to insufficient information. Thus, these three studies are not included within this section of the analysis. Due the limited number of studies, we could not conduct a meta-regression.

\section{Impact of study features on effect sizes}

There were insufficient comparisons involving patient outcomes to enable a meta-regression of study features and the magnitude of the effects (Fig. 3). Below, we report on the findings of the subgroup analysis.

\section{Study design}

Given that observational studies are generally at a higher risk of bias than non-randomised studies, we compared the results of randomised and non-randomised studies. The pooled treatment effect for the randomised trials $(n=2049)$ was, on average, RR 0.97 [95\% CI 0.71 to 1.34$]$. There were five randomised trials included in the analysis, and the findings are likely to be driven by one randomised trial which found an increase in the number of negative events and was stopped early [50]. The difference in the between subgroup effects for the randomised trials and controlled before-after studies was statistically significant. The controlled before-after studies generated a greater average treatment effect in favour of care bundles than the randomised trials $(n=119,178 ; \mathrm{RR}=0.66$ [95\% CI 0.59 to 0.75$]$ ). However, the quality of the evidence was very low quality (downgraded for risk of bias, inconsistency and indirectness). 


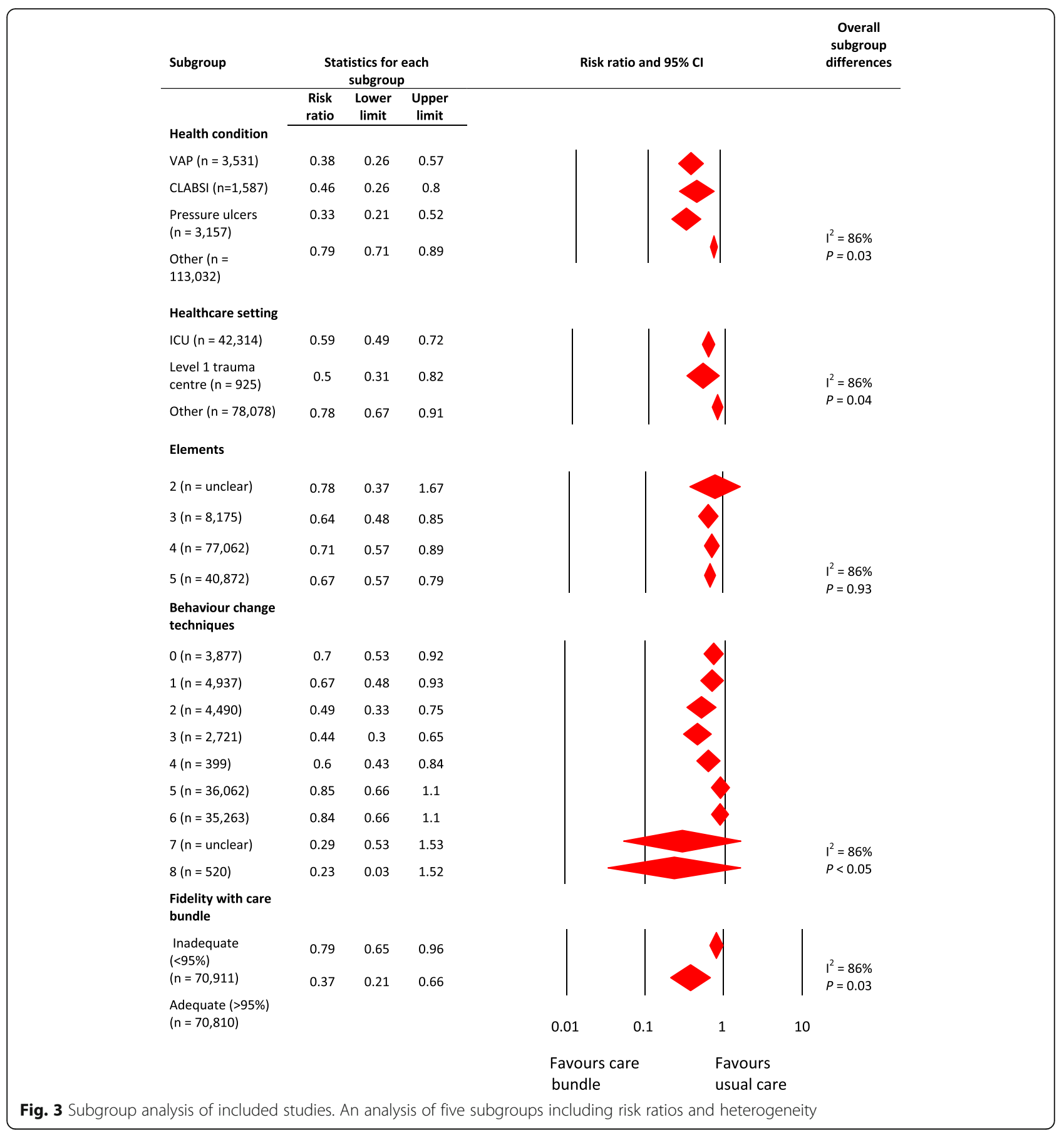

\section{Health condition}

We grouped studies by their target health condition to assess impact (Fig. 3). The care bundles appeared to be potentially effective in all of the conditions we evaluated (including a heterogeneous 'other' group). The test for differences between subgroups was statistically significant $(P<0.001)$ suggesting that there were differences in effects between the subgroups. The studies assessing the effects of care bundles on the incidence of pressure ulcers, central line-associated bloodstream infections and ventilator-associated pneumonia may have the largest reductions in the risk of negative patient outcomes. A small reduction was observed for the heterogeneous 'other' category. However, we considered all these data to be of very low quality due to risk of bias, inconsistency and indirectness.

\section{Healthcare setting}

The data also suggested care bundles were potentially effective across all of the settings in which they were 
evaluated (Fig. 3). Care bundles may be more effective in trauma and ICUs compared with the heterogeneous 'other' group. However, this is very low quality evidence (downgraded for risk of bias, inconsistency and indirectness).

\section{Care bundle elements of care}

We assessed whether the number of elements of care within the care bundle impacted on patient outcomes (Fig. 3). Whilst all care bundles (regardless of the number of elements) reduced the risk of the negative patient outcomes, the test for differences between the subgroups was not statistically significant $(P=0.93)$. The $R R$ was similar irrespective of the number of elements. For example, for three elements, the RR was 0.64 [95\% CI 0.48 to 0.85 ] and for five elements, the risk ratio was 0.67 [95\% CI 0.57 to 0.79$]$. However, the quality of evidence within this subgroup was very low (downgraded for risk of bias, inconsistency and indirectness).

\section{Behaviour change techniques}

The frequency with which the behaviour change techniques were delivered was often not reported nor were the levels of engagement with the behaviour change techniques. We assessed the impact of the number of behaviour change techniques on the effectiveness of care bundles. There were significant variations between the subgroups and the lowest risk for the negative patient outcomes was in the subgroup with 'eight behaviour change techniques' ( $R R=0.23$ [95\% CI 0.03 to 1.52]) (Fig. 3). The apparent effect of care bundles appeared to reduce as the number of elements increased (the care bundles with five elements had an RR of 0.85 [95\% CI 0.66 to 1.1]). However, we considered these data to be of very low quality due to risk of bias, inconsistency and indirectness.

\section{Fidelity with the care bundle}

Fidelity with the care bundle elements was regarded as adequate at $95 \%$ or above. As hypothesised, adequate fidelity (three studies) may be associated with a larger effect on patient outcomes ( $R R=0.37$ [95\% CI 0.21 to $0.66]$ ) when compared with inadequate fidelity ( $R R=$ 0.82 [ $95 \%$ CI 0.66 to 1.0]). However, the evidence was of very low quality which was downgraded for risk of bias, inconsistency and indirectness.

\section{Discussion}

This systematic review was the first step towards gaining an extensive understanding of care bundles in general. We have identified a large, heterogeneous body of research which shows that care bundles may be an effective intervention for improving patient outcomes in acute settings (e.g. preventing ventilator-associated pneumonia in ICUs). However, the certainty of our conclusion is greatly tempered by the low or very low quality of the evidence (with most of the evidence coming from controlled before-after studies). We have shown that the care bundles evaluated using the non-randomised designs are more likely to report greater patient benefits. This is likely to be due, at least in part, to the biases in the study design and conduct. Unfortunately, the evidence from the randomised trials was uncertain (five studies with a total sample size of $N=2049$ ).

Existing systematic reviews of care bundles are condition or setting-specific and suggest that care bundles may be effective in preventing and managing a range of conditions such as sepsis [28], central line-associated bloodstream infections [30] and chronic obstructive pulmonary disease [26]. Others focussed on hospital settings $[36,38,86]$. Across all of the existing reviews, the certainty of the evidence was deemed to be low and the high risk of bias in the included studies continues to be reported, limiting the certainty of the conclusions about the effectiveness of care bundles.

It was difficult to assess the effect of fidelity to the care bundles on patient outcomes. Thirteen studies reported levels of fidelity with the care bundle. Levels of adherence varied between the studies suggesting that the full implementation of the elements of care included in the care bundles was rare. This is an important issue as three studies demonstrated fewer occurrences of the negative events (central line-associated bloodstream infections [62], mortality [73] and surgical site infections [60]) when fidelity with the care bundle was high. However, within the analysis, we were generally working with uncertain data, and review findings must be considered in line with the observational nature of subgroup analysis. As noted previously, the quality of the evidence is very low and therefore, we are uncertain whether there was an underlying effect of care bundles that is independent of these study characteristics.

A systematic review of 47 non-randomised studies [29], reporting the strategies used to facilitate the implementation of care bundles employed on ICUs, found the most frequently used strategies were audit and feedback, education and reminders. Unfortunately, the findings were inconclusive as implementation fidelity was rarely reported and the certainty of the evidence was assessed as being low. Thus, it was not possible to determine the most effective strategies used to improve the uptake of the care bundles. These findings are similar to those reported in this review and in a review of 14 studies (five controlled trials, two interrupted time series studies, seven controlled before-after studies) evaluating the effectiveness of chronic obstructive pulmonary disease discharge care bundles [26]. The poor reporting of the implementation fidelity issues may restrict the utility 
and reproducibility of the systematic review findings [87]. Thus, clear reporting of intervention components and of implementation fidelity are essential to the complete interpretation of data about the effectiveness of behaviour change interventions.

The lack of theory in the development and implementation of the care bundles was evident throughout the systematic review. Eight studies reported using an implementation framework or a psychological theory to guide their implementation [53, 59, 66, 74-77, 83]. When encouraging healthcare workers to use evidence-based strategies, taking a theory-informed approach is recommended [19, 88]. However, often a pragmatic approach is taken, and this lack of explicit psychological theory during the design and implementation phases of the care bundle may impact on the effectiveness of such interventions [89-91].

Mechanisms of action are the theoretical constructs through which behaviour change techniques have their effect. Explicitly stating the potential mechanisms of action (e.g. restructuring the environment, training) can facilitate the generalisation of the care bundle findings to other healthcare settings. The most commonly used behaviour change techniques were 'feedback and monitoring' and 'shaping knowledge'. This is in line with previous findings on implementation strategies [37, 92, 93]. However, the frequency of these behaviour change techniques was often not reported, and neither were the levels of engagement with the behaviour change techniques (e.g. attendance at training sessions), or the mechanisms of action. Thus, conclusions regarding the effectiveness of using the behaviour change techniques to facilitate a change in the behaviours of healthcare workers were not possible.

\section{Limitations}

Our systematic review had some limitations. Firstly, we did not explore the strength of the evidence underpinning the care bundles. It is possible that the elements themselves have contributed to the heterogeneity, but it was not within the scope of the current review to assess the content of the care elements. Secondly, behaviour change techniques used in each study were coded retrospectively according to the Behaviour Change Technique Taxonomy Version 1 [22]. Thus, we are unsure whether these behaviour change techniques were intentionally used to increase the uptake of the care bundles.

Finally, our search terms were broad and the data are heterogeneous with high variability among health conditions, settings, care bundle elements and outcomes, thus the comparisons are limited. Existing systematic reviews have taken a more narrow, condition or setting-specific approach, so reducing the potential for drawing overall conclusions about the effects of care bundles. One of the aims of the systematic review was to evaluate the evidence of care bundles in general to assess the generalisability and consistency of the research findings across a wide range of study populations. As the review question was broad, we did not apply narrow inclusion criteria for the systematic review which is likely to have increased the number of eligible studies and allowed a more detailed exploration of heterogeneity as well as reducing the likelihood of type I error [94].

By 'lumping' studies together initially, a more detailed understanding of care bundles was possible through the subgroup analyses (specified a priori). The subgroup analysis assisted in strengthening the process as the advantages of lumping and splitting were combined [95]. Whilst the existing reviews provide information about the effectiveness of care bundles in highly specified situations, there is little understanding of their effects in general. Consequently, this systematic review was the first step towards identifying and addressing gaps in the care bundle literature. However, taking such a broad scope was problematic for two reasons. Firstly, it was likely to have increased the level of statistical heterogeneity. Secondly, it was difficult to balance the impact of the exploration with the clarity required for a meta-analysis. A cautious approach to interpreting the findings from the subgroup analysis is necessary as they are observational in nature [44] and therefore are at risk of bias through confounding by other studylevel characteristics [96].

\section{Future research}

This systematic review has highlighted interesting but very low quality data. The need for clear and unambiguous reporting has been highlighted during this review especially with regards to who is delivering the care bundle and the content of the implementation intervention. The TIDieR checklist for interventions [97] needs to be followed more rigorously.

\section{Conclusions}

Very low quality evidence from controlled before-after studies (downgraded due to the risk of bias, inconsistencies and potential indirectness of outcomes) suggests that the implementation of care bundles may be an effective strategy to improve patient outcomes when compared with usual care. By contrast, the low-quality evidence from five randomised trials (downgraded due to the risk of bias, inconsistencies and potential indirectness of outcomes) is highly uncertain. Future research should focus on the explicit and transparent reporting of the implementation of the care bundle including issues relating to implementation fidelity such as the frequency with which the behaviour change techniques were used. The higher quality reporting of the research findings will enable stronger conclusions to be drawn about the effectiveness of care bundles. 


\section{Additional files}

Additional file 1: Search terms. Search strategy performed in each database. (DOCX $27 \mathrm{~kb}$ )

Additional file 2: Summary of included studies [98-108]. (DOCX 76 kb) Additional file 3: Summaries of risk of bias. Review authors' judgements about each risk of bias item presented as percentages across all included studies. (DOCX $17 \mathrm{~kb}$ )

\section{Abbreviations}

CBAs: Controlled before-and-after studies; Cl: Confidence interval; ICU: Intensive care unit; MD: Mean differences; RCTs: Randomised controlled trials; RR: Risk ratio; SMD: Standardised mean difference

\section{Acknowledgements}

This project was funded by the National Institute for Health Research Collaboration for Leadership in Applied Health Research and Care (NIHR CLAHRC) Greater Manchester. The NIHR CLAHRC Greater Manchester is a partnership between providers and commissioners from the NHS, industry and the third sector, as well as clinical and research staff from the University of Manchester. The views expressed in this article are those of the authors and not necessarily those of the NHS, NIHR or the Department of Health.

\section{Funding}

No external funding.

\section{Availability of data and materials}

All data generated or analysed during this study are included in this published review.

\section{Authors' contributions}

$J$ developed, designed, and coordinated the review; performed the screening process, extracted data, conducted the quality assessment, analysed and interpreted data, performed statistical analysis, completed drafting and revisions of the review and approved final version before submission. TG performed data extraction, conducted quality assessment, contributed to the interpretation of the data, assisted with drafting and revising the review and approved final version before submission. JD contributed to the statistical analysis and interpretation of data, assisted with drafting and revising the review, and approved final version before submission. WR performed the screening process, extracted data, conducted the quality assessment and approved final version before submission. NC contributed to the conception and design of the review, contributed to the statistical analysis and interpretation of the data, assisted with drafting and revising the review and approved final version before submission. All authors read and approved the final manuscript.

\section{Ethics approval and consent to participate}

Not applicable.

\section{Consent for publication}

Not applicable.

\section{Competing interests}

The authors declare that they have no competing interests.

\section{Publisher's Note}

Springer Nature remains neutral with regard to jurisdictional claims in published maps and institutional affiliations.

\section{Author details}

'Division of Nursing, Midwifery and Social Work, University of Manchester, Manchester Academic Health Science Centre, Room 3.331, Jean McFarlane Building, Oxford Road, Manchester M13 9PL, England. ${ }^{2}$ Collaboration for Leadership in Applied Health Research and Care (CLAHRC) Greater Manchester, Manchester, England. ${ }^{3}$ Manchester Centre for Health Psychology, University of Manchester, Manchester, England. ${ }^{4}$ Primary Care \& Research Services, Keele University, Newcastle-under-Lyme, England. ${ }^{5}$ Research and
Innovation Division, Manchester University NHS Foundation Trust, Manchester Academic Health Science Centre, Manchester, England.

Received: 24 April 2017 Accepted: 13 November 2017

Published online: 29 November 2017

\section{References}

1. Eccles MP, Mittman BS. Welcome to implementation science. Implement Sci. 2006;1(1):1.

2. Deedwania P. Gaps in guideline implementation: a cause for concern, time for action. J Am Coll Cardiol. 2015:65(3):278-80.

3. Runciman WB, Hunt TD, Hannaford NA, Hibbert PD, Westbrook II, Coiera EW, et al. CareTrack: assessing the appropriateness of health care delivery in Australia. Med J Aust. 2012;197(10):549.

4. Pentland D, Forsyth K, Maciver D, Walsh M, Murray R, Irvine L, et al. Key characteristics of knowledge transfer and exchange in healthcare: integrative literature review. J Adv Nurs. 2011;67(7):1408-25.

5. Dixon-Woods M, McNicol S, Martin G. Ten challenges in improving quality in healthcare: lessons from the Health Foundation's programme evaluations and relevant literature. BMJ Qual Saf. 2012;21(10):876-84:bmjqs-2011-000760.

6. Jun J, Kovner CT, Stimpfel AW. Barriers and facilitators of nurses' use of clinical practice guidelines: an integrative review. Int J Nurs Stud. 2016; 60:54-68

7. McKee G, Kerins M, Hamilton G, Hansen T, Hendriks J, Kletsiou E, et al. Barriers to ESC guideline implementation: results of a survey from the European Council on Cardiovascular Nursing and Allied Professions (CCNAP). Eur J Cardiovasc Nurs. 2017;1:1-9:1474515117710097.

8. Waring J, Allen D, Braithwaite J, Sandall J. Healthcare quality and safety: a review of policy, practice and research. Sociol Health IIIn. 2016;38(2): 198-215.

9. Baker R, Camosso-Stefinovic J, Gillies C, Shaw EJ, Cheater F, Flottorp S, et al. Tailored interventions to overcome identified barriers to change: effects on professional practice and health care outcomes. Cochrane Database Syst Rev. 2010;3(3):1-86.

10. McKee G, Codd M, Dempsey O, Gallagher P, Comiskey C. Describing the implementation of an innovative intervention and evaluating its effectiveness in increasing research capacity of advanced clinical nurses: using the consolidated framework for implementation research. BMC Nurs. 2017;16(1):21.

11. Paget S, Lilischkis K, Morrow A, Caldwell P. Embedding research in clinical practice: differences in attitudes to research participation among clinicians in a tertiary teaching hospital. Intern Med J. 2014;44(1):86-9.

12. Colquhoun HL, Squires JE, Kolehmainen N, Fraser C, Grimshaw JM. Methods for designing interventions to change healthcare professionals' behaviour: a systematic review. Implement Sci. 2017;12(1):30.

13. French SD, Green SE, O'Connor DA, McKenzie JE, Francis JJ, Michie S, et al. Developing theory-informed behaviour change interventions to implement evidence into practice: a systematic approach using the theoretical domains framework. Implement Sci. 2012;7(1):38

14. Luker JA, Bernhardt J, Graham ID, Middleton S, Lynch EA, Thayabaranathan $\mathrm{T}$, et al. Interventions for the uptake of evidence-based recommendations in acute stroke settings. Cochrane Libr. 2017:1:1-22

15. Resar R, Pronovost P, Haraden C, Simmonds T, Rainey T, Nolan T. Using a bundle approach to improve ventilator care processes and reduce ventilator-associated pneumonia. Jt Comm J Qual Patient Saf. 2005; 31(5):243-8.

16. Resar R, Griffin F, Haraden C, Nolan T. Using care bundles to improve health care quality. $\mid \mathrm{H}$ innovation series white paper Cambridge. Massachusetts: Institute for Healthcare Improvement; 2012

17. Steinmo SH, Michie S, Fuller C, Stanley S, Stapleton C, Stone SP. Bridging the gap between pragmatic intervention design and theory: using behavioural science tools to modify an existing quality improvement programme to implement "sepsis six". Implement Sci. 2016;11:14.

18. Zingg W, Holmes A, Dettenkofer M, Goetting T, Secci F, Clack L, et al. Hospital organisation, management, and structure for prevention of healthcare-associated infection: a systematic review and expert consensus. Lancet Infect Dis. 2015:15(2):212-24.

19. Craig P, Dieppe P, Macintyre S, Michie S, Nazareth I, Petticrew M. Developing and evaluating complex interventions: the new Medical Research Council guidance. BMJ. 2008;337:a1655. 
20. Michie S, Abraham C, Eccles MP, Francis JJ, Hardeman W, Johnston M. Strengthening evaluation and implementation by specifying components of behaviour change interventions: a study protocol. Implement Sci. 2011;6(1):10.

21. Michie S, Johnston M. Theories and techniques of behaviour change: developing a cumulative science of behaviour change. Health Psychology Review. 2012;6(1):1-6.

22. Michie S, Richardson M, Johnston M, Abraham C, Francis J, Hardeman W, et al. The behavior change technique taxonomy ( $v 1$ ) of 93 hierarchically clustered techniques: building an international consensus for the reporting of behavior change interventions. Ann Behav Med. 2013;46(1):81-95.

23. Michie S, Fixsen D, Grimshaw JM, Eccles MP. Specifying and reporting complex behaviour change interventions: the need for a scientific method. Implement Sci. 2009;4(1):40.

24. Presseau J, Ivers NM, Newham JJ, Knittle K, Danko KJ, Grimshaw JM. Using a behaviour change techniques taxonomy to identify active ingredients within trials of implementation interventions for diabetes care. Implement Sci. 2015;10(1):55.

25. Michie S, Johnston M, Francis J, Hardeman W, Eccles M. From theory to intervention: mapping theoretically derived behavioural determinants to behaviour change techniques. Appl Psychol. 2008;57(4):660-80.

26. Ospina MB, Mrklas K, Deuchar L, Rowe BH, Leigh R, Bhutani M, et al. A systematic review of the effectiveness of discharge care bundles for patients with COPD. Thorax. 2017;72(1):31-9.

27. Tanner J, Padley W, Assadian O, Leaper D, Kiernan M, Edmiston C. Do surgical care bundles reduce the risk of surgical site infections in patients undergoing colorectal surgery? A systematic review and cohort metaanalysis of 8,515 patients. Surgery. 2015;158(1):66-77.

28. Damiani E, Donati A, Serafini G, Rinaldi L, Adrario E, Pelaia P, et al. Effect of performance improvement programs on compliance with sepsis bundles and mortality: a systematic review and meta-analysis of observational studies. PLoS One. 2015;10(5):e0125827.

29. Schweizer M, Perencevich E, McDanel J, Carson J, Formanek M, Hafner $J$, et al. Effectiveness of a bundled intervention of decolonization and prophylaxis to decrease Gram positive surgical site infections after cardiac or orthopedic surgery: systematic review and meta-analysis. $\mathrm{Br}$ Med J. 2013:346:13.

30. Ista E, van der Hoven B, Kornelisse RF, van der Starre C, Vos MC, Boersma $E$, et al. Effectiveness of insertion and maintenance bundles to prevent central-line-associated bloodstream infections in critically ill patients of all ages: a systematic review and meta-analysis. Lancet Infect Dis. 2016;16(6):724-34.

31. Payne $V$, Johnson M, Smith S, Hall M. Care bundles to reduce central line-associated bloodstream infections (CLABSI) in the neonatal intensive care unit (NICU): a systematic review and meta-analyses. Eur J Pediatr. 2016;175(11):1482-3.

32. Chamberlain DJ, Willis EM, Bersten AB. The severe sepsis bundles as processes of care: a meta-analysis. Aust Crit Care. 2011;24(4):229-43.

33. Schweizer ML, Reisinger HS, Ohl M, Formanek MB, Blevins A, Ward MA, et al. Searching for an optimal hand hygiene bundle: a meta-analysis. Clin Infect Dis. 2014;58(2):248-59.

34. Ferrer R, Artigas A. Effectiveness of treatments for severe sepsis: data from the bundle implementation programs. Minerva Anestesiol. 2011;77(3):360-5.

35. Aboelela SW, Stone PW, Larson EL. Effectiveness of bundled behavioural interventions to control healthcare-associated infections: a systematic review of the literature. J Hosp Infect. 2007;66(2):101-8.

36. Marwick C, Davey P. Care bundles: the holy grail of infectious risk management in hospital? Curr Opin Infect Dis. 2009;22(4):364-9.

37. Borgert MJ, Goossens A, Dongelmans DA. What are effective strategies for the implementation of care bundles on ICUs: a systematic review. Implement Sci. 2015;10(1):119.

38. Bannan DF, Tully MP. Bundle interventions used to reduce prescribing and administration errors in hospitalized children: a systematic review. J Clin Pharm Ther. 2016:41(3):246-55.

39. Moher D, Liberati A, Tetzlaff J, Altman DG, Group P. Preferred reporting items for systematic reviews and meta-analyses: the PRISMA statement. PLoS Med. 2009;6(7):e1000097.

40. Cohen J. A coefficient of agreement for nominal scales. Educ Psychol Meas. 1960;20(1):37-46.

41. Higgins JP, Altman DG, Gøtzsche PC, Jüni P, Moher D, Oxman AD, et al. The Cochrane Collaboration's tool for assessing risk of bias in randomised trials. BMJ. 2011;343:d5928.
42. Sterne JAC, Higgins JPT, Reeves BC, ACROBAT-NRSI. obotdgf. A Cochrane Risk of Bias Assessment Tool: for Non-Randomised Studies of Interventions (ACROBAT-NRSI) www.riskofbias.info 2014 [1.0.0] Available from: http://www. riskofbias.info. Accessed 24 Feb 2017.

43. Higgin J, Thompson S, Deeks J, Altman D. Measuring inconsistency in meta-analysis. Br Med J. 2003;327:557-60.

44. Deeks J, Higgins J, Altman D. 9.5. 2 identifying and measuring heterogeneity. The Cochrane handbook for systematic reviews of interventions version. 2011;5(0).

45. Kontopantelis E, Springate DA, Reeves D. A re-analysis of the Cochrane Library data: the dangers of unobserved heterogeneity in meta-analyses. PLoS One. 2013;8(7):e69930.

46. Comprehensive Meta Analysis 2006-2017 [Available from: https://www meta-analysis.com/. Accessed 27 Feb 2017.

47. Kraemer HC, Wilson GT, Fairburn CG, Agras WS. Mediators and moderators of treatment effects in randomized clinical trials. Arch Gen Psychiatry. 2002;59(10):877-83.

48. Pincus T, Miles C, Froud R, Underwood M, Carnes D, Taylor SJ. Methodological criteria for the assessment of moderators in systematic reviews of randomised controlled trials: a consensus study. BMC Med Res Methodol. 2011;11(1):14.

49. Jennings $J H$, Thavarajah $K$, Mendez MP, Eichenhorn M, Kvale $P$, Yessayan L. Predischarge bundle for patients with acute exacerbations of COPD to reduce readmissions and ED visits: a randomized controlled trial. Chest. 2015;147(5):1227-34

50. Anthony T, Murray B, Sum-Ping J, Lenkovsky F, Vornik V, Parker B, et al. Evaluating an evidence-based bundle for preventing surgical site infection: a randomized trial. Arch Surg. 2011;146(3):263-9. Available from: http://onlinelibrary.wiley.com/o/cochrane/clcentral/articles/435/CN00779435/frame.html

51. Loftus RW, Brindeiro BS, Kispert DP, Patel HM, Koff MD, Jensen JT, et al. Reduction in intraoperative bacterial contamination of peripheral intravenous tubing through the use of a passive catheter care system. Anesth Analg. 2012;115(6):1315-23.

52. Chipps EM, Carr M, Kearney R, MacDermott J, Visger TV, Calvitti K, et al. Outcomes of an oral care protocol in Postmechanically ventilated patients. Worldviews Evid-Based Nurs. 2016;13(2):102-11.

53. Power M, Tyrrell PJ, Rudd AG, Tully MP, Dalton D, Marshall M, et al. Did a quality improvement collaborative make stroke care better? A cluster randomized trial. Implement Sci. 2014;9(1):40.

54. Chaboyer W, Bucknall T, Webster J, McInnes E, Gillespie BM, Banks M, et al. The effect of a patient centred care bundle intervention on pressure ulcer incidence (INTACT): a cluster randomised trial. Int J Nurs Stud. 2016;64:63-71.

55. Stolbrink M, McGowan L, Saman H, Nguyen T, Knightly R, Sharpe J, et al. The early mobility bundle: a simple enhancement of therapy which may reduce incidence of hospital-acquired pneumonia and length of hospital stay. J Hosp Infect. 2014;88(1):34-9.

56. Al-Tawfiq JA, Abed MS. Decreasing ventilator-associated pneumonia in adult intensive care units using the Institute for Healthcare Improvement bundle. Am J Infect Control. 2010;38(7):552-6.

57. Anderson M, Finch Guthrie P, Kraft W, Reicks P, Skay C, Beal AL. Universal pressure ulcer prevention bundle with WOC nurse support. J Wound Ostomy Continence Nurs. 2015;42(3):217-25.

58. Antworth A, Collins CD, Kunapuli A, Klein K, Carver P, Gandhi T, et al. Impact of an antimicrobial stewardship program comprehensive care bundle on management of candidemia. Pharmacotherapy. 2013;33(2):137-43.

59. El Azab SR, Sayed AEE, Abdelkarim M, Mutairi KBA, Saqabi AA, Demerdash SE. Combination of ventilator care bundle and regular oral care with chlorhexidine was associated with reduction in ventilator associated pneumonia. Egypt J Anaesth. 2013;29(3):273-7.

60. Schweizer ML, Chiang HY, Septimus E, Moody J, Braun B, Hafner J, et al. Association of a bundled intervention with surgical site infections among patients undergoing cardiac, hip, or knee surgery. JAMA. 2015; 313(21):2162-71. Available from: http://onlinelibrary.wiley.com/o/ cochrane/clcentral/articles/221/CN-01071221/frame.html

61. Eom JS, Lee M-S, Chun H-K, Choi HJ, Jung S-Y, Kim Y-S, et al. The impact of a ventilator bundle on preventing ventilator-associated pneumonia: a multicenter study. Am J Infect Control. 2014;42(1):34-7.

62. Hakko E, Guvenc S, Karaman I, Cakmak A, Erdem T, Cakmakci M. Long-term sustainability of zero central-line associated bloodstream infections is possible with high compliance with care bundle elements. East Mediterr Health J. 2015;21(4):293-8. 
63. Hocking C, Pirret AM. Using a combined nursing and medical approach to reduce the incidence of central line associated bacteraemia in a New Zealand critical care unit: a clinical audit. Intensive Crit Care Nurs. 2013;29(3): 137-46.

64. Jeong IS, Park SM, Lee JM, Song JY, Lee SJ. Effect of central line bundle on central line-associated bloodstream infections in intensive care units. Am J Infect Control. 2013:41(8):710-6.

65. Lindsay ME, Hovan MJ, Deming JR, Hunt VL, Witwer SG, Fedraw LA, et al. Improving hypertension control in diabetes: a multisite quality improvement project that applies a 3-step care bundle to a chronic disease care model for diabetes with hypertension. Am J Med Qual. 2013;28(5):365-73.

66. Conway-Morris A, Hay AW, Swann DG, Everingham K, McCulloch C, McNulty $J$, et al. Reducing ventilator-associated pneumonia in intensive care: impact of implementing a care bundle. Crit Care Med. 2011;39(10):2218-24.

67. Muszynski JA, Sartori J, Steele L, Frost R, Wang W, Khan N, et al. Multidisciplinary quality improvement initiative to reduce ventilator-associated tracheobronchitis in the PICU. Pediatr Crit Care Med. 2013;14(5):533-8.

68. Resende DS, O JM, DvDd B, VOS A, Gontijo Filho PP. Reduction of catheterassociated bloodstream infections through procedures in newborn babies admitted in a university hospital intensive care unit in Brazil. Rev Soc Bras Med Trop. 2011;44(6):731-4.

69. Schindler CA. More than S.K.I.N. Deep: decreasing pressure ulcer development in the pediatric intensive care unit: Marquette University; 2010. Available from: http://epublications.marquette.edu/cgi/viewcontent.cgi?article=1084\&context= dissertations_mu. Accessed 16 Jan 2016.

70. Stano P, Avolio M, De Rosa R, Modolo ML, Camporese A. Methicillinresistant Staphylococcus aureus infection rate after implementation of an antibiotic care bundle based on results of rapid molecular screening. In Vivo. 2013;27(6):873-6

71. Subramanian $\mathrm{P}$, Choy KL, Gobal SV, Mansor M, Ng KH. Impact of education on ventilator-associated pneumonia in the intensive care unit. Singap Med J. 2013:54(5):281-4

72. Lawrence P, Fulbrook P. Effect of feedback on ventilator care bundle compliance: before and after study. Nurs Crit Care. 2012;17(6):293-301.

73. Levy MM, Rhodes A, Phillips GS, Townsend SR, Schorr CA, Beale R, et al. Surviving sepsis campaign: association between performance metrics and outcomes in a 7.5-year study. Intensive Care Med. 2014;40(11):1623-33.

74. Berenholtz SM, Pham JC, Thompson DA, Needham DM, Lubomski LH, Hyzy $\mathrm{RC}$, et al. Collaborative cohort study of an intervention to reduce ventilatorassociated pneumonia in the intensive care unit. Infect Control Hosp Epidemiol. 2011;32(4):305-14

75. Battersby C, Santhakumaran S, Upton M, Radbone L, Birch J, Modi N. The impact of a regional care bundle on maternal breast milk use in preterm infants: outcomes of the East of England quality improvement programme. Arch Dis Child Fetal Neonatal Ed. 2014;99(5):F395-401.

76. Boesch RP, Myers C, Garrett T, Nie A, Thomas N, Chima A, et al. Prevention of tracheostomy-related pressure ulcers in children. Pediatrics. 2012;129(3):e792-7.

77. Smith CD, Grami P. Feasibility and effectiveness of a delirium prevention bundle in critically ill patients. Am J Crit Care. 2017;26(1):19-27.

78. Düzkaya D, Bozkurt G, Uysal G, Yakut T. The effects of bundles on catheterassociated urinary tract infections in the pediatric intensive care unit. Clin Nurse Spec. 2016;30(6):341-6.

79. Lim KP, Kuo SW, Ko WJ, Sheng WH, Chang YY, Hong MC, et al. Efficacy of ventilator-associated pneumonia care bundle for prevention of ventilatorassociated pneumonia in the surgical intensive care units of a medical center. J Microbiol Immunol Infect. 2015:48(3):316-21.

80. Steiner M, Langgartner M, Cardona F, Waldhor T, Schwindt J, Haiden N, et al. Significant reduction of catheter-associated blood stream infections in preterm neonates after implementation of a care bundle focusing on simulation training of central line insertion. Pediatr Infect Dis J. 2015;34(11):1193-6.

81. Salama MF, Jamal W, Al Mousa H, Rotimi V. Implementation of central venous catheter bundle in an intensive care unit in Kuwait: effect on central lineassociated bloodstream infections. J Infect Public Health. 2016;9(1):34-41.

82. Pena-Lopez Y, Pujol M, Campins M, Gonzalez-Antelo A, Rodrigo JA, Balcells $J$, et al. Implementing a care bundle approach reduces ventilator-associated pneumonia and delays ventilator-associated tracheobronchitis in children: differences according to endotracheal or tracheostomy devices. Int J Infect Dis. 2016;52:43-8.

83. Huddart S, Peden C, Swart M, McCormick B, Mohammed M, Quiney N, et al. ELPQuiC (emergency Laparotomy pathway quality improvement care-bundle): reducing mortality after emergency major general surgery. Anaesthesia. 2014;69:14

84. Roquilly A, Cinotti R, Jaber S, Vourc'h M, Pengam F, Mahe PJ, et al. Implementation of an evidence-based extubation readiness bundle in 499 brain-injured patients: a before-after evaluation of a quality improvement project. Am J Respir Crit Care Med. 2013;188(8):958-66.

85. Rinke ML, Bundy DG, Chen AR, Milstone AM, Colantuoni E, Pehar M, et al. Central line maintenance bundles and CLABSIs in ambulatory oncology patients. Pediatrics. 2013;132(5):e1403-12.

86. Luangasanatip N, Hongsuwan M, Limmathurotsakul D, Lubell Y, Lee AS, Harbarth S, et al. Comparative efficacy of interventions to promote hand hygiene in hospital: systematic review and network meta-analysis. BMJ. 2015:351:h3728.

87. Hoffmann TC, Oxman AD, loannidis JP, Moher D, Lasserson TJ, Tovey DI, et al. Enhancing the usability of systematic reviews by improving the consideration and description of interventions. BMJ. 2017;358:j2998.

88. National Institute for Health and Care Excellecnce. Behaviour change: individual approaches [PH49] 2014 [Available from: https://www.nice.org.uk] guidance/ph49. Accessed 1 Nov 2017.

89. Davies P, Walker AE, Grimshaw JM. A systematic review of the use of theory in the design of guideline dissemination and implementation strategies and interpretation of the results of rigorous evaluations. Implement Sci. 2010;5(1):14.

90. Michie S, Johnston M, Abraham C, Lawton R, Parker D, Walker A. Making psychological theory useful for implementing evidence based practice: a consensus approach. Qual Saf Health Care. 2005;14(1):26-33.

91. Group ICEtBR. Designing theoretically-informed implementation interventions. Implement Sci. 2006;1(1):4.

92. Dijkstra MG, Van Zummeren M, Rozendaal L, Van Kemenade FJ, Helmerhorst TJM, Snijders PJF, et al. Safety of extending screening intervals beyond five years in cervical screening programmes with testing for high risk human papillomavirus: 14 year follow-up of population based randomised cohort in the Netherlands. BMJ. 2016;355(8076):1.

93. Sinuff T, Muscedere J, Adhikari NK, Stelfox HT, Dodek P, Heyland DK, et al, Knowledge translation interventions for critically ill patients: a systematic review. Crit Care Med. 2013:41(11):2627-40.

94. Weir MC, Grimshaw JM, Mayhew A, Fergusson D. Decisions about lumping vs. splitting of the scope of systematic reviews of complex interventions are not well justified: a case study in systematic reviews of health care professional reminders. J Clin Epidemiol. 2012;65(7):756-63.

95. Squires JE, Valentine JC, Grimshaw JM. Systematic reviews of complex interventions: framing the review question. J Clin Epidemiol. 2013;66(11): $1215-22$.

96. Sun X, Briel M, Walter SD, Guyatt GH. Is a subgroup effect believable? Updating criteria to evaluate the credibility of subgroup analyses. BMJ. 2010; 340:c117.

97. Hoffmann TC, Glasziou PP, Boutron I, Milne R, Perera R, Moher D, et al. Better reporting of interventions: template for intervention description and replication (TIDieR) checklist and guide. BMJ. 2014;348:g1687.

98. Bevan H, Plesk P, Winstanle L. Leading large scale change: a practical guide: Institute for Innovation and Improvement NHS; 2011. Availbale from: http://theedge.nhsiq.nhs.uk/2821-2/. Accessed 21 Mar 2017.

99. Langley GJ, Nolan KM, W NT, Norman CL, Provost LP. The improvement guide: a practical approach to enhancing organizational performance. San Francisco: Jossey-Bass; 1996.

100. Association AWM. Pan Pacific clinical practice guideline for the prevention and management of pressure injury. Osborne Park: Cambridge Media; 2012. p. 1-124.

101. Chou R, Dana T, Bougatsos C, Blazina I, Starmer AJ, Reitel K, et al. Pressure ulcer risk assessment and prevention. A systematic comparative effectiveness review. Ann Intern Med. 2013;159(1):28-38.

102. Niederhauser A, Lukas CV, Parker V, Ayello EA, Zulkowski K, Berlowitz D. Comprehensive programs for preventing pressure ulcers: a review of the literature. Adv Skin Wound Care. 2012;25(4):167-88.

103. Reddy M, Gill SS, Rochon PA. Preventing pressure ulcers: a systematic review. J Am Med Assoc. 2006;296(8):974-84.

104. Soban LM, Hempel S, Munjas BA, Miles J, Rubenstein LV. Preventing pressure ulcers in hospitals: a systematic review of nurse-focused quality improvement interventions. Jt Comm J Qual Patient Saf. 2011;37(6):245-AP16.

105. Sullivan N, Schoelles KM. Preventing in-facility pressure ulcers as a patient safety strategy. A systematic review. Ann Intern Med. 2013;158:410-6. 
106. O'Keefe-McCarthy S, Santiago C, Lau G. Ventilator-associated pneumonia bundled strategies: an evidence-based practice. Worldviews Evid-Based Nurs. 2008;5(4):193-204.

107. Langley GJ, Moen RD, Nolan KM, Nolan TW, Norman CL, Provost LP. The improvement guide: a practical approach to enhancing organizational performance. 2nd ed. San Fransisco: Jossey-Bass; 2009.

108. Henderson V. Nursing theories: a companion to nursing theories and models. http://currentnursing.com/nursing_theory/Henderson.html. Accessed 7 Apr 2017.

Submit your next manuscript to BioMed Central and we will help you at every step:

- We accept pre-submission inquiries

- Our selector tool helps you to find the most relevant journal

- We provide round the clock customer support

- Convenient online submission

- Thorough peer review

- Inclusion in PubMed and all major indexing services

- Maximum visibility for your research

Submit your manuscript at www.biomedcentral.com/submit 